\title{
Arctic sea-ice change: a grand challenge of climate science
}

\author{
Vladimir M. KATTSOV, ${ }^{1}$ Vladimir E. RYABININ, ${ }^{2}$ James E. OVERLAND, ${ }^{3}$ \\ Mark C. SERREZE, ${ }^{4}$ Martin VISBECK, ${ }^{5}$ John E. WALSH, ${ }^{6}$ Walt MEIER, ${ }^{4}$ \\ Xiangdong ZHANG $^{6}$ \\ ${ }^{1}$ Voeikov Main Geophysical Observatory (MGO), Roshydromet, 7 Karbyshev Street, 190421 St Petersburg, Russia \\ E-mail: kattsov@mail.ru \\ ${ }^{2}$ World Climate Research Programme (WCRP), World Meteorological Organization, 7 bis, avenue de la Paix, \\ Case Postale 2300, CH-1211 Geneva 2, Switzerland \\ ${ }^{3}$ Pacific Marine Environmental Laboratory (PMEL), National Oceanic and Atmospheric Administration, 7600 Sand Point Way, \\ NE Bldg. 3, Seattle, Washington 98115-6349, USA \\ ${ }^{4}$ National Snow and Ice Data Center, University of Colorado, 1540 30th Street, Boulder, Colorado 80309-0449, USA \\ ${ }^{5}$ Leibniz-Institut für Meereswissenschaften (IFM-GEOMAR), Düsternbrooker Weg 20, D-24105 Kiel, Germany \\ ${ }^{6}$ International Arctic Research Center, University of Alaska Fairbanks, PO Box 757340, Fairbanks, Alaska 99775-7340, USA
}

\begin{abstract}
Over the period of modern satellite observations, Arctic sea-ice extent at the end of the melt season (September) has declined at a rate of $>11 \%$ per decade, and there is evidence that the rate of decline has accelerated during the last decade. While climate models project further decreases in seaice mass and extent through the 21st century, the model ensemble mean trend over the period of instrumental records is smaller than observed. Possible reasons for the apparent discrepancy between observations and model simulations include observational uncertainties, vigorous unforced climate variability in the high latitudes, and limitations and shortcomings of the models stemming in particular from gaps in understanding physical process. The economic significance of a seasonally sea-ice-free future Arctic, the increased connectivity of a warmer Arctic with changes in global climate, and large uncertainties in magnitude and timing of these impacts make the problem of rapid sea-ice loss in the Arctic a grand challenge of climate science. Meaningful prediction/projection of the Arctic sea-ice conditions for the coming decades and beyond requires determining priorities for observations and model development, evaluation of the ability of climate models to reproduce the observed sea-ice behavior as a part of the broader climate system, improved attribution of the causes of Arctic sea-ice change, and improved understanding of the predictability of sea-ice conditions on seasonal through centennial timescales in the wider context of the polar climate predictability.
\end{abstract}

\section{INTRODUCTION}

Over the period of modern satellite observations (1979present), Arctic sea-ice extent at the end of the melt season (September) has declined at a rate of $>11 \%$ per decade, and there is evidence that the rate of decline has accelerated during the last decade. Every September since 1996 the seaice extent has been below the 1979-99 mean. Ice extent for September 2010 was the third lowest in the satellite record for the month, behind 2007 (lowest) and 2008 (second lowest) (US National Snow and Ice Data Center (NSIDC), http://nsidc.org/arcticseaicenews/2010/100410.htm, 2010). For the last 4 years, September ice extent has been below two standard deviations below the long-term climatic mean. The winter ice extent has also been declining, but at a slower rate, although 2011's winter maximum ice extent was close to the lowest in the satellite record. The sea-ice cover is also thinning (e.g. Rothrock and others, 1999). According to Kwok and others (2009), the Arctic Ocean has lost $40 \%$ of its multiyear ice in the last 5 years. At the end of summer $2010,<15 \%$ of the ice remaining in the Arctic was $>2$ years old, compared to $50-60 \%$ during the 1980s (NSIDC, http://nsidc.org/ arcticseaicenews/2010/100410.htm). There is virtually none of the oldest (at least 5 years old) ice remaining in the Arctic $\left(<60000 \mathrm{~km}^{2}\right.$, compared to $2 \times 10^{6} \mathrm{~km}^{2}$ during the $\left.1980 \mathrm{~s}\right)$.

The generation of coupled global atmosphere-ocean general circulation models (AOGCMs) that participated in the World Climate Research Programme's (WCRP) Coupled
Model Intercomparison Project phase 3 (CMIP3) was the main source of climate projections assessed by the Intergovernmental Panel on Climate Change (IPCC) in its Fourth Assessment Report (AR4: Solomon and others, 2007). While there is a significant inter-model scatter in simulations and projections of the Arctic sea ice (Arzel and others, 2006; Zhang and Walsh, 2006; Kattsov and others, 2007), all models project decreasing ice mass and extent throughout the 21 st century. For the most aggressive greenhouse-gas (GHG) emission scenarios (e.g. A2), some of the CMIP3 models project an ice-free Arctic Ocean in late summer by the end of the century. A number of studies suggest that the Arctic Ocean may lose nearly all of its multi-year sea-ice cover by the mid-21st century (Holland and others, 2006; Stroeve and others, 2007; Alekseev and others, 2009; Wang and Overland, 2009; Zhang, 2010). However, as an ensemble, the CMIP3 AOGCMs are apparently conservative in simulating the observed trend of September ice extent (Fig. 1; Stroeve and others, 2007).

The future of Arctic sea-ice cover is of enormous climatic and economic significance (e.g. ACIA, 2005). Due to several climatic feedbacks involving sea ice, the ability of climate models to realistically project the future of the Arctic sea ice is an important condition for adequately projecting the global climate (e.g. Bony and others, 2006).

The main goal of this paper is to consider possible reasons for the apparent discrepancy between observation and model 


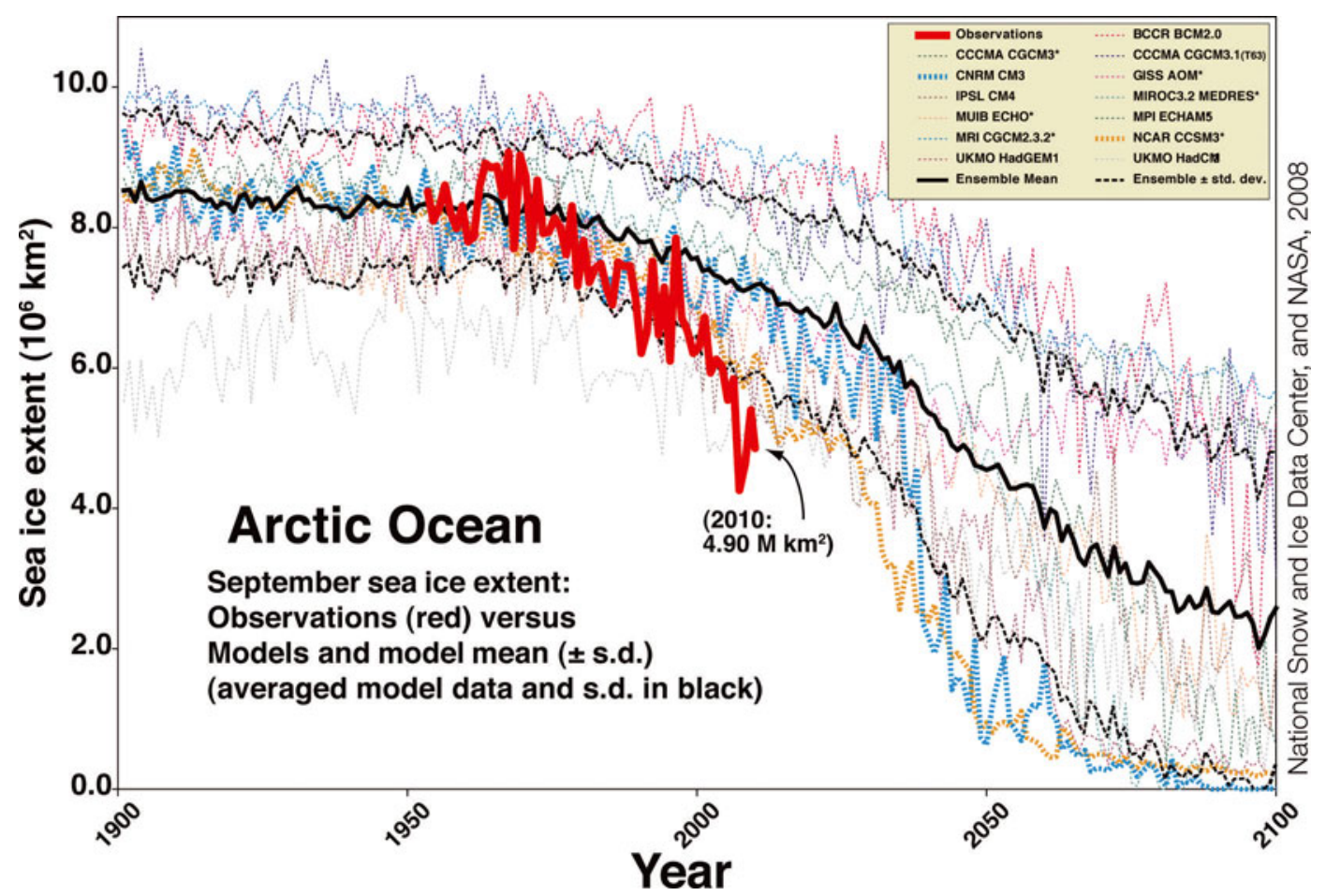

Fig. 1. Arctic September sea-ice extent from observations (thick red line) and 13 CMIP3 models, together with the multi-model ensemble mean (solid black line) and one standard deviation range of model estimates (dotted black line). Models with more than one ensemble member are indicated with an asterisk. Note that these are September means, not yearly minima. (Adapted from Stroeve and others, 2007; courtesy of J. Stroeve.)

simulations, and to suggest steps towards minimizing uncertainties in predicting/projecting the future of the Arctic sea ice.

\section{OBSERVATION UNCERTAINTIES}

Addressing the problem of rapid sea-ice loss requires accurate information on ice thickness, velocity, age, salinity, density, snow cover and other factors. Data on some of these variables are absolutely necessary, while records for others are helpful. Satellite passive microwave (PMW) sensors are the main data source for estimating sea-ice extent and concentration. The accuracy of PMW retrieval algorithms has been examined in many studies (e.g. Meier, 2005; Andersen and others, 2007; Meier and Stroeve, 2008); differences in total Arctic sea-ice extent from different algorithms are as large as $1 \times 10^{6} \mathrm{~km}^{2}$ (Fig. 2). While the studies just mentioned have identified a variety of limitations of individual algorithms under certain environmental conditions, no single algorithm has been demonstrated to be consistently superior. Most differences between algorithm products are fairly consistent through time, so trends and anomalies are generally in better agreement. However, for model intercomparisons, the absolute extent is important. Hence there is a clear need for further product intercomparison and verification.

It is even more difficult to assess uncertainties in sea-ice thickness estimates. Both the analysis of satellite-derived sea-ice age data and a new proxy record of ice thickness for past decades (Maslanik and others, 2007; Kwok and Rothrock, 2009; Kwok and others, 2009) suggest that in addition to an overall reduction of multi-year ice cover in the Arctic, the mean age and thickness of the remaining multi-year ice has decreased, reflecting primarily the loss of the oldest ice types. The remaining relatively old and thick ice is now confined to a much smaller portion of the Arctic Ocean near northern Canada than in the earlier years. Given this, the sea-ice cover is increasingly susceptible to pronounced summer ice loss or an anomalous ice drift.

Climate model evaluation requires data on the oceanic and atmospheric conditions. Global reanalyses, such as ERA-40, ERA-Interim and JRA-25, are presently the best sources of gridded atmospheric data. Significant attention has been given to improving their accuracy in the Arctic. Shortcomings in representation of the Arctic precipitation are particularly problematic (Serreze and Hurst, 2000). While assimilated variables constrain some fields (e.g. sealevel pressure) in a reanalysis, almost all model-computed fields in an atmospheric reanalysis have substantial errors in the Arctic (Walsh and others, 2009). The ongoing Arctic System Reanalysis (Bromwich and others, 2010) may help to address some of these shortcomings, but a continuing issue is the lack of direct mid-tropospheric observations. New datasets, to be produced by the International Polar Year (IPY) projects, several European Space Agency projects (e.g. Globlce, GlobSnow, GlobGlacier, GlobPermafrost), the CryoClim project, various research groups, composites of cryospheric parameters generated by the Global Interagency IPY Polar Snapshot Year (GIIPSY) project, and output of several other related activities will provide a useful database for verification studies. Observations directed at identifying and quantifying the physical processes, especially feedbacks, are the highest priority.

Many ocean regions have seen systematic data synthesis efforts spearheaded by the WCRP CLIVAR project and its Global Synthesis and Observations Panel (GSOP). At present, there is no attempt to produce a long-term ocean 


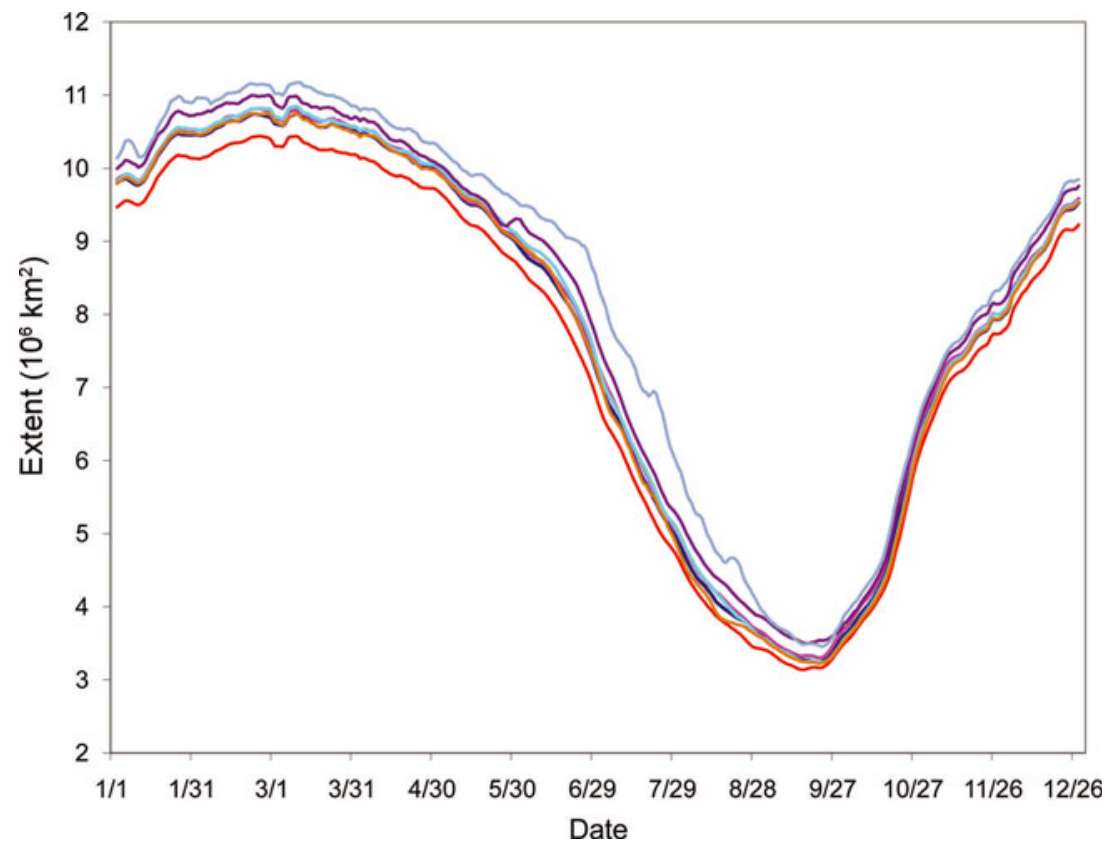

Fig. 2. Arctic sea-ice extent for 2007 from seven algorithm products. Common quality-control filtering and land masks are employed so that differences in values are due to algorithm differences or the source data. Extent is defined as the total area covered by at least $15 \%$ concentration of sea ice. Dates are month/day.

data synthesis for either the Arctic Ocean or the Southern Ocean. Quantifying changes in sensible heat storage in the upper ocean is of particular importance. In addition, deterministic model simulations targeting predictability of the ocean-atmosphere system require accurate initializations of the polar oceans.

\section{MODEL UNCERTAINTIES}

The sensitivity of AOGCM sea-ice components to GHG forcing has been a research focus for more than a decade. Simple zero- through one-dimensional thermodynamic parameterizations of sea ice were the state of the art in the mid-1990s and reflected in AOGCMs that took part in CMIP and CMIP2, earlier phases of the Coupled Model Intercomparison Experiment. Such parameterizations were found to be overly sensitive to external forcing. Emerging dynamic-thermodynamic models offered the potential for a major improvement in the sensitivity over the thermodynamic models (Hilmer and Lemke, 2000).

Two of the major developments in modeling over the past decade have been the implementation of sea-ice dynamics in almost all AOGCMs and a sea-ice thickness distribution in some of them (Randall and others, 2007). Sea-ice components of CMIP3 AOGCMs usually predict ice thickness (or volume), fractional cover, snow depth, surface and internal temperatures (or energy) and horizontal velocity. Sea-ice albedo is typically prescribed, with only crude dependence on ice thickness, snow cover and puddling effects. The complexity of sea-ice dynamics varies from the relatively simple 'cavitating fluid' approach to more comprehensive viscous-plastic and elastic-viscous-plastic models. Sea-ice thermodynamics modules in climate models typically use constant conductivity and heat capacities for ice and snow (if represented) and do not account for effects of brine pockets in the ice. Some models include snow ice formation, which occurs when a part of the ice floe is submerged under the weight of the overlying snow and the flooded snow layer refreezes. As a significant advance over the previous decade, a few modern sea-ice models, even with relatively high resolution, incorporate subgrid-scale ice thickness distributions with several thickness 'categories', rather than considering the ice as a uniform slab with inclusions of open water. Although parameterizations of ridging mechanics and their relationship with the ice thickness distribution have improved, inclusion of advanced ridging parameterizations has lagged development of other aspects of sea-ice dynamics (rheology, in particular) owing to a lack of observational constraints.

The most reliably measured characteristic of sea ice for model evaluation is still sea-ice extent. Despite the significant differences between models, the CMIP3 multi-model mean of sea-ice extent in the Northern Hemisphere agrees reasonably well with observations (Fig. 3). The simulated mean extent (calculated from all gridcells with an ice concentration above $15 \%$ ) exceeds observed values by up to $\sim 1 \times 10^{6} \mathrm{~km}^{2}$ throughout the year (Arzel and others, 2006; Fig. 4). This difference is with respect to the Hadley Centre sea-ice and sea surface temperature (HadISST) dataset (Rayner and others, 2003), and is of the same order as differences between various sea-ice extent products (see discussion above). In many models, however, the regional distribution of sea ice is poorly simulated, even if the hemispheric extent is approximately correct (Arzel and others, 2006; Zhang and Walsh, 2006). The biases may influence the model climate sensitivity (Holland and others, 2003; Wang and Overland, 2009).

Among the primary causes of biases in simulated sea-ice extent, especially its geographical distribution, are problems with high-latitude winds (Bitz and others, 2002), ocean heat advection, and vertical and horizontal mixing in the ocean (Arzel and others, 2006). Also important are errors in surface energy fluxes (Sorteberg and others, 2007), which may result from inadequate parameterizations of the atmospheric 

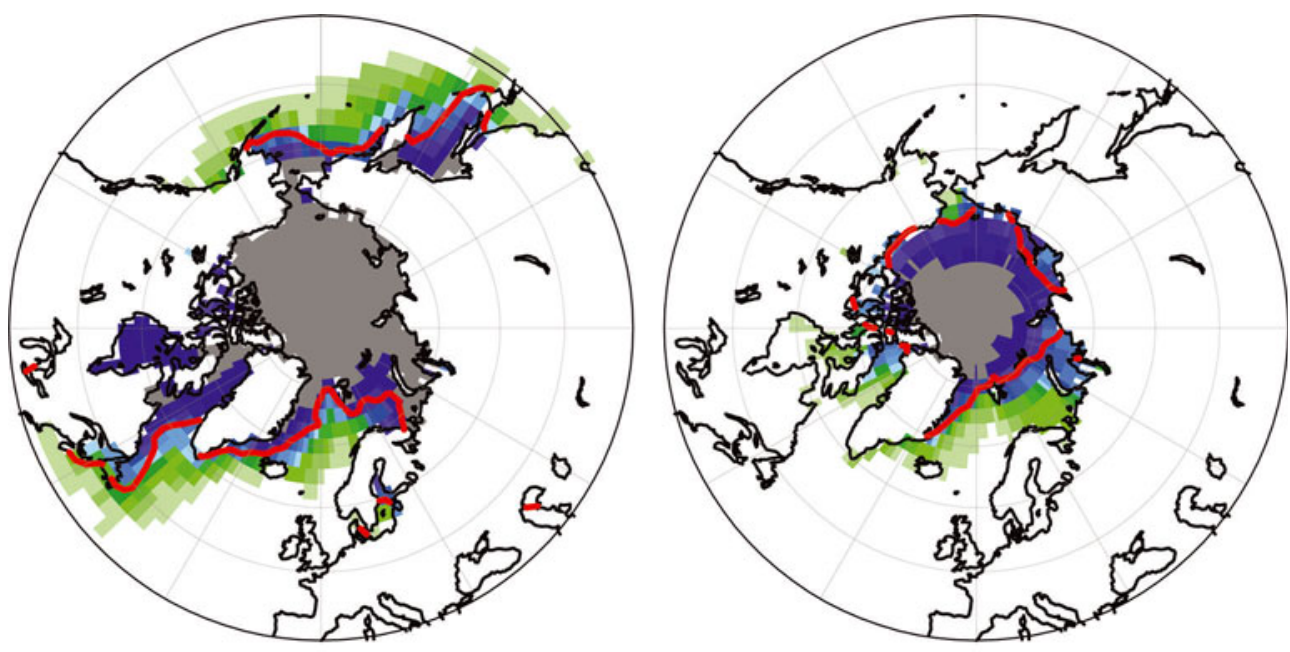

$\begin{array}{lllllllllllllllll}1 & 2 & 3 & 4 & 5 & 6 & 7 & 8 & 9 & 10 & 11 & 12 & 13 & 14 & 15 & 16 & 17\end{array}$

Fig. 3. Current climate (1980-99) sea-ice extent $\left(\times 10^{6} \mathrm{~km}^{2}\right)$ in the Northern Hemisphere as simulated by 17 CMIP3 models for March (left) and September (right). For each $2.5^{\circ} \times 2.5^{\circ}$ longitude-latitude gridcell, the figure indicates the number of models that simulate at least $15 \%$ of the area covered by sea ice. The observed 15\% concentration boundaries (red line) are based on the Hadley Centre sea ice and sea surface temperature (HadISST; Rayner and others, 2003) dataset. (Adapted from Arzel and others, 2006; Randall and others, 2007; courtesy of T. Pavlova.)

boundary layer in the Arctic and from generally poor simulation of high-latitude cloudiness which is evident from the large inter-model scatter (Vavrus and others, 2009). Ice transport out of the Arctic Ocean through the Fram Strait (e.g. Tsukernik and others, 2010) also needs to be adequately represented in AOGCMs. Getting this transport correct is critically dependent on proper simulation of the surface wind field.

\section{NATURAL VARIABILITY AND PREDICTABILITY}

One likely contributor to the observed rapid decline of the Arctic ice extent and thickness is natural multi-year and decadal climate variability. This includes factors such as changes in heat storage in the upper layer of the ocean during

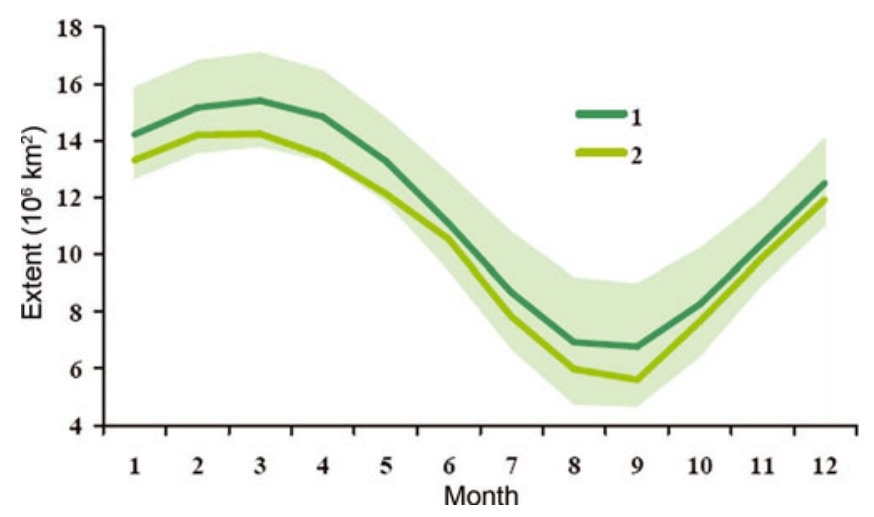

Fig. 4. Current climate (1980-99) sea-ice extent seasonal cycle in the Northern Hemisphere as simulated by 17 CMIP3 models (1) and observed (2). The observed extent estimates are based on the HadISST (Rayner and others, 2003) dataset. The shaded area shows the one standard deviation range of the model ensemble. (Adapted from Kattsov and others, 2007.) the summer, and ocean heat transport from the Atlantic and Pacific to the Arctic Ocean. Due to their coarse resolution, the AOGCMs tend to underestimate the amount of heat delivered to the sea ice by the horizontal oceanic transport.

There are a number of ways in which sea ice is influenced by and interacts with the atmosphere and ocean, and the nature and magnitude of associated feedbacks, both positive and negative, are still poorly quantified (e.g. US NRC, 2003; Overland and Wang, 2010). Potentially important smallscale processes, such as convection in brine pockets or in melt ponds, are not included in the sea-ice components of current AOGCMs. Possible impacts of black carbon aerosols that induce atmospheric warming and black carbon on snow and ice that decreases the surface albedo (e.g. AMAP, 2009) have so far only been examined in idealized model simulations (e.g. Hansen and Nazarenko, 2004).

In principle, the possibility exists that the sharp downward trend in ice extent is a statistically rare event associated with natural (unforced) climate variability. While the abrupt 1 year ice loss that occurred in 2007 has received much attention, the observational record in Figure 1 shows that there was an equally large (albeit more reversible) 1 year increase in the mid-1990s. Until concentrations of GHGs reach higher values, climate signals from natural variability may be comparable in magnitude to those from external forcing. The CMIP3 ensemble arguably does not have enough members to capture low-probability events. Additionally, the CMIP3 models appear to have limited abilities to generate unforced atmospheric variability with magnitudes comparable to observations (e.g. the major Arctic warming event from the 1920s through the 1940s (Wang and others, 2007)). On the other hand, at least some of the CMIP3 models do simulate rapid changes in the Arctic sea ice due mainly to natural variability. The timing of the rapid ice decline events simulated by a model cannot be expected to match that observed, but at least the general character of the simulated (rapid) changes in some models resembles 
well the observed behavior of the ice cover. Together with the possibility that the observational data for 1953-78 (pre-satellite) overestimate the earlier ice extent, climate model hindcasts may well be reasonably accurate.

Because of the obviously different quality of model performance in simulation of different variables and for different regions, development of strategies for optimizing regional projections based on 'ensembles of opportunity', such as the CMIP3 multi-model ensemble, is urgently needed. The problem of selection of subsets of models aimed at narrowing the range of plausible climate projections is far from trivial (e.g. Walsh and others, 2008; Zhang, 2010; Overland and others, in press). In particular, developing a proven set of metrics for model discrimination through comparisons of model simulations with observations remains high on the agenda of model evaluation (Randall and others, 2007).

Improving predictions of sea-ice conditions on seasonal through interannual timescales also bears on predicting the longer-term (century-long) fate of the ice cover. The eventual goal is a timescale-independent 'seamless prediction' system. Motivated by recent dramatic changes in Arctic sea-ice extent, several groups (e.g. Drobot, 2007; Lindsay and others, 2008; Zhang and others, 2008) have started to issue seasonal forecasts. So far these efforts have been either purely statistical or have used a sea-ice-ocean model with atmospheric forcing prescribed from past years to predict the future sea-ice cover. These methods show promise because sea-ice anomalies exhibit autocorrelation, with several months' lag for the sea-ice extent (Drobot and others 2006; Lindsay and others, 2008; Blanchard-Wrigglesworth and others, 2010) and several years' lag for the sea-ice volume (Bitz and others, 1996; L'Hévéder and Houssais, 2001; Flato and others, 2003). Mixed-layer heat storage in the ocean also offers some additional predictability (Lindsay and others, 2008). A number of other groups are providing seasonal predictions of seasonal minimum extent for the SEARCH (Study of Environmental Arctic Change) Sea Ice Outlook project. These groups also use a combination of statistical and uncoupled model estimates and expert knowledge. Only one group appears to use the statistics from a fully coupled model, and none uses a coupled climate system model.

Seasonal to multi-year predictability of Arctic sea-ice cover, as well as that of the entire Arctic climate system, remains an important outstanding issue. A limited number of recent studies (Koenigk and Mikolajewicz, 2008; Döscher and others, 2009; Holland and others, in press) provide hope for a possibility of predicting trajectories of aspects of the sea-ice system on the seasonal timescale and even beyond.

\section{CONCLUSIONS}

Predicting the evolution of the Arctic sea-ice cover is a grand challenge of climate science. Meaningful prediction/projection requires progress in several interconnected avenues of research and observations including:

Determining priorities of observational and modeling developments (e.g. dedicated ice thickness satellite missions, sea-ice modeling allowing data assimilation);

Improved understanding of inherent limits to predicting the state of the sea-ice cover on seasonal, interannual, decadal and centennial timescales in the wider context of the polar climate predictability;
Attribution of the causes of Arctic sea-ice change (i.e. quantification of the interplay of its forced and unforced aspects) and evaluation of the ability of the state-of-theart climate models to reproduce the observed sea-ice behavior as a part of the broader climate system (including developing model metrics to be used to constrain projections through comparison of simulations with observations), with as full as possible accounting of ice-atmosphere-ocean processes, interactions and feedbacks.

The new phase of the Coupled Model Intercomparison Project (CMIP5: K. Taylor and others, http://cmip-pcmdi.Ilnl.gov/cmip5/experiment_design.html?submenuheader=1) will provide the nearest opportunity to address some of these issues. CMIP5 as a framework for coordinated climate change experiments for the next several years includes simulations for assessment in the IPCC Fifth Assessment Report (AR5) as well as others that extend beyond the AR5.

Predictions and hindcasts on seasonal through decadal timescales will require model initialization, which was not done for the CMIP3 simulations. Drawing conclusions about the success or failure in hindcasting the observed loss of the Arctic ice will require reliable regional observations to initialize a number of fields, such as the sea-ice thickness distribution (because of the strong impact of the initial seaice thickness on the change in ice extent), and to enable verification. The same is true for the thermohaline structure of the ocean. In the absence of the data needed for the initialization, a possibility of generating a proxy of initial conditions through the use of regional models of the Arctic Ocean forced with the observed (reanalyzed) atmospheric fields could be explored (Gerdes and Köberle, 2007). Some ongoing activities, such as the Arctic System Reanalysis, promise an important contribution towards solving this problem. It should be stressed, however, that even with the necessary data in hand, the initialization of the coupled atmosphere-ice-ocean system is a serious challenge in itself, in addition to the notorious problem of the coupled model drift (e.g. Kattsov and others, 2005).

The record sea-ice extent minimum over the satellite record took place in September 2007, during the IPY 200708. IPY efforts, many of which are ongoing, have generated a wealth of data. Also, there have been several projects directed at Arctic system prediction, including sea ice. Nevertheless, there has yet to be a study that would unify the efforts of the climate research community to analyze available data in their entirety and use them to improve the prediction of Arctic climate at different timescales. Such a study could benefit from a synthesis of work at very high resolution (e.g. a new Surface Heat Budget of the Arctic Ocean (SHEBA)-like campaign - to better understand local processes, include sea-ice biogeochemical connections and validate various remote-sensing algorithms), but should focus on regional and Arctic-wide observational, modeling, and data synthesis efforts. Such an initiative could become a cornerstone for the proposed International Polar Decade. An inventory of all Arctic data would help in initiating this major synthesizing activity.

\section{ACKNOWLEDGEMENTS}

We acknowledge the modeling groups, the Program for Climate Model Diagnosis and Intercomparison (PCMDI) and 
the WCRP's Working Group on Coupled Modelling (WGCM), for their roles in making available the WCRP CMIP3 multi-model dataset. Support of this dataset is provided by the Office of Science, US Department of Energy. This paper benefited from discussions during the International Arctic Research Center (IARC)-Climate and Cryosphere Project (CliC) joint workshop 'Rapid Change in Arctic Sea Ice: Assessing Drivers and Future Trajectories' (6-8 October 2010, IARC, Fairbanks, Alaska, USA). V.M.K. and J.E.W. were supported by US National Science Foundation (NSF) grant OPP-0652838, and V.M.K. additionally by the Research Council of Norway ARCWARM project and Russian Foundation for Basic Research (RFBR) grant 0805-00569. J.E.O. appreciates the support of the Arctic Program of the US National Oceanic and Atmospheric Administration (NOAA) Climate Office, PMEL contribution No. 3627. M.C.S. was supported by NSF grant ARC0901962. W.M. was supported by NOAA grant No. NA07OAR4310056. X.Z. was supported by the Japan Agency for Marine-Earth Science and Technology (JAMSTEC) and NSF through grant ARC-1023592. We thank the anonymous reviewer.

\section{REFERENCES}

Alekseev, G.V., A.I. Danilov, V.M. Kattsov, S.I. Kuz'mina and N.E. Ivanov. 2009. Changes in the climate and sea ice of the Northern Hemisphere in the 20th and 21st centuries from data of observations and modeling. Izv. Atmos. Ocean. Phys., 45(6), 675-686.

Andersen, S., R. Tonboe, L. Kaleschke, G. Heygster and L.T. Pedersen. 2007. Intercomparison of passive microwave sea ice concentration retrievals over the high-concentration Arctic sea ice. J. Geophys. Res., 112(C8), C08004. (10.1029/ 2006JC003543.)

Arctic Climate Impact Assessment (ACIA). 2005. Arctic climate impact assessment: scientific report. Cambridge, etc., Cambridge University Press.

Arctic Monitoring and Assessment Programme (AMAP). 2009. Update on selected climate issues of concern: observations, short-lived climate forcers, Arctic carbon cycle, and predictive capability. Oslo, Arctic Monitoring and Assessment Programme.

Arzel, O., T. Fichefet and H. Goosse. 2006. Sea ice evolution over the 20th and 21 st centuries as simulated by current AOGCMs. Ocean Model., 12(3-4), 401-415.

Bitz, C.M., D.S. Battisti, R.E. Moritz and J.A. Beesley. 1996. Lowfrequency variability in the Arctic atmosphere, sea ice, and upper-ocean climate system. J. Climate, 9(2), 394-408.

Bitz, C.M., J.C. Fyfe and G.M. Flato. 2002. Sea ice response to wind forcing from AMIP models. J. Climate, 15(5), 522-536.

Blanchard-Wrigglesworth, E., K.C. Armour and C.M. Bitz. 2010. Persistence and inherent predictability of Arctic sea ice in a GCM ensemble and observations. J. Climate, 24(1), 231-250.

Bony, S. and 13 others. 2006. How well do we understand and evaluate climate change feedback processes? J. Climate, 19(15), 3445-3482.

Bromwich, D. and 7 others. 2010. Arctic system reanalysis: call for community involvement. Eos, 91(2), 13.

Döscher, R., K. Wyser, H.E.M. Meier, M. Qian and R. Redler. 2009. Quantifying Arctic contributions to climate predictability in a regional coupled ocean-ice-atmosphere model. Climate Dyn., 34 (7-8), 1157-1176.

Drobot, S.D. 2007. Using remote sensing data to develop seasonal outlooks for Arctic regional sea-ice minimum extent. Remote Sens. Environ., 111(2-3), 136-147.
Drobot, S.D., J.A. Maslanik and C. Fowler. 2006. A long-range forecast of Arctic summer sea-ice minimum extent. Geophys. Res. Lett., 33(10), L10501. (10.1029/2006GL026216.)

Flato, G.M. and CMIP Modelling Groups. 2003. Sea-ice and its response to $\mathrm{CO}_{2}$ forcing as simulated by global climate models. Climate Dyn., 23(3-4), 229-241.

Gerdes, R. and C. Köberle. 2007. Comparison of Arctic sea ice thickness variability in IPCC Climate of the 20th Century experiments and in ocean-sea ice hindcast. J. Geophys. Res., 112(C4), C04S13. (10.1029/2006JC003616.)

Hansen, J.E. and L. Nazarenko. 2004. Soot climate forcing via snow and ice albedos. Proc. Natl Acad. Sci. USA (PNAS), 101(2), 423-428.

Hilmer, M. and P. Lemke. 2000. On the decrease of Arctic sea ice volume. Geophys. Res. Lett., 27(22), 3751-3754.

Holland, M.M., C.M. Bitz and B. Tremblay. 2006. Future abrupt reductions in the summer Arctic sea ice. Geophys. Res. Lett., 33(23), L23503. (10.1029/2006GL028024.)

Holland, M.M., D.A. Bailey and S. Vavrus. In press. Inherent sea ice predictability in the rapidly changing Arctic environment of the Community Climate System Model, version 3. Climate Dyn. (10.1007/s00382-010-0792-4.)

Kattsov, V.M. and 10 others. 2005. Future climate change: modeling and scenarios for the Arctic. In Arctic Climate Impact Assessment, Arctic climate impact assessment: scientific report. Cambridge, etc., Cambridge University Press, 99-150.

Kattsov, V.M., G.V. Alekseev, T.V. Pavlova, P.V. Sporyshev, R.V. Bekryaev and V.A. Govorkova. 2007. Modeling the evolution of the world ocean ice cover in the 20th and 21st centuries. Izv. Atmos. Ocean. Phys., 43(2), 142-157.

Koenigk, T. and U. Mikolajewicz. 2008. Seasonal to interannual climate predictability in mid and high northern latitudes in a global coupled model. Climate Dyn., 32(6), 783-798.

Kwok, R. and D.A. Rothrock. 2009. Decline in Arctic sea ice thickness from submarine and ICESat records: 1958-2008. Geophys. Res. Lett., 36(15), L15501. (10.1029/2009GL039035.)

Kwok, R., G.F. Cunningham, M. Wensnahan, I. Rigor, H.J. Zwally and D. Yi. 2009. Thinning and volume loss of the Arctic Ocean sea ice cover: 2003-2008. J. Geophys. Res., 114(C7), C07005. (10.1029/2009JC005312.)

L'Hévéder, B. and M.-N. Houssais. 2001. Investigating the variability of the Arctic sea ice thickness in response to a stochastic thermodynamic atmospheric forcing. Climate Dyn., 17(2-3), 107-125

Lindsay, R.W., J. Zhang, A.J. Schweiger and M.A. Steele. 2008. Seasonal predictions of ice extent in the Arctic Ocean. J. Geophys. Res., 113(C2), C02023. (10.1029/2007JC00425.)

Maslanik, J.A., C. Fowler, J. Stroeve, S. Drobot and H.J. Zwally. 2007. A younger, thinner Arctic ice cover: increased potential for rapid, extensive ice loss. Geophys. Res. Lett., 34(24), L24501. (10.1029/2007GL032043.)

Meier, W.N. 2005. Comparison of passive microwave ice concentration algorithm retrievals with AVHRR imagery in Arctic peripheral seas. IEEE Trans. Geosci. Remote Sens., 43(6), 1324-1337.

Meier, W.N. and J. Stroeve. 2008. Comparison of sea-ice extent and ice-edge location estimates from passive microwave and enhanced-resolution scatterometer data. Ann. Glaciol., 48, 65-70.

Overland, J.E. and M. Wang. 2010. Large-scale atmospheric circulation changes are associated with the recent loss of Arctic sea ice. Tellus, 62(1), 1-9.

Overland, J.E., M. Wang, N. Bond, J. Walsh, V. Kattsov and W. Chapman. In press. Considerations in the selection of global climate models for regional climate projections: the Arctic as a case study. J. Climate.

Randall, D.A. and 12 others. 2007. Climate models and their evaluation. In Solomon, S. and 7 others, eds. Climate change 2007: the physical science basis. Contribution of Working Group I to the Fourth Assessment Report of the Intergovern- 
mental Panel on Climate Change. Cambridge, etc., Cambridge University Press, 589-662.

Rayner, N.A. and 7 others. 2003. Global analyses of sea surface temperature, sea ice, and night marine air temperature since the late nineteenth century. J. Geophys. Res., 108(D14), 4407. (10.1029/2002JD002670.)

Rothrock, D.A., Y. Yu and G.A. Maykut. 1999. Thinning of the Arctic sea-ice cover. Geophys. Res. Lett., 26(23), 3469-3472.

Serreze, M.C. and C.M. Hurst. 2000. Representation of mean Arctic precipitation from NCEP-NCAR and ERA reanalyses. J. Climate, 13(1), 182-201.

Solomon, S. and 7 others, eds. 2007. Climate change 2007: the physical science basis. Contribution of Working Group I to the Fourth Assessment Report of the Intergovernmental Panel on Climate Change. Cambridge, etc., Cambridge University Press.

Sorteberg, A., V. Kattsov, J.E. Walsh and T. Pavlova. 2007. The Arctic surface energy budget as simulated with the IPCC AR4 AOGCMs. Climate Dyn., 29(2-3), 131-156.

Stroeve, J., M.M. Holland, W. Meier, T. Scambos and M. Serreze. 2007. Arctic sea ice decline: faster than forecast. Geophys. Res. Lett., 34(9), L09501. (10.1029/2007GL029703.)

Tsukernik, M., C. Deser, M. Alexander and R. Tomas. 2010. Atmospheric forcing of Fram Strait sea ice export: a closer look. Climate Dyn., 35(7-8), 1349-1360.

United States National Research Council (US NRC). 2003. Understanding climate change feedbacks. Washington, DC, National Academies Press.
Vavrus, S., D. Waliser, A. Schweiger and J. Francis. 2009. Simulations of 20th and 21st century Arctic cloud amount in the global climate models assessed in the IPCC AR4. Climate Dyn., 33(7-8), 1099-1115.

Walsh, J.E., W.L. Chapman, V. Romanovsky, J.H. Christensen and M. Stendel. 2008. Global climate model performance over Alaska and Greenland. J. Climate, 21(23), 6156-6174.

Walsh, J.E., W.L. Chapman and D.H. Portis. 2009. Arctic cloud fraction and radiative fluxes in atmospheric reanalyses. J. Climate, 22(9), 2316-2334.

Wang, M. and J.E. Overland. 2009. A sea-ice free summer Arctic within 30 years? Geophys. Res. Lett., 36(7), L07502. (110.1029/ 2009GL037820.)

Wang, M., J.E. Overland, V. Kattsov, J.E. Walsh, X. Zhang and T. Pavlova. 2007. Intrinsic versus forced variation in coupled climate model simulations over the Arctic during the twentieth century. J. Climate, 20(6), 1093-1107.

Zhang, X. 2010. Sensitivity of arctic summer sea ice coverage to global warming forcing: towards reducing uncertainty in arctic climate change projections. Tellus, 62A(3), 220-227.

Zhang, X. and J.E. Walsh. 2006. Toward a seasonally ice-covered Arctic ocean: scenarios from the IPCC AR4 model simulations. J. Climate, 19(9), 1730-1747.

Zhang, J., M. Steele, R. Lindsay, A. Schweiger and J. Morison. 2008. Ensemble 1-year predictions of Arctic sea ice for the spring and summer of 2008. Geophys. Res. Lett., 35(8), L08502. (10.1029/ 2008GL033244.) 